\title{
ASSESSING THE VISUAL IMPACTS OF SURFACE MINING: A SYSTEMATIC REVIEW
}

\author{
Maria Menegaki \\ School of Mining and Metallurgy Engineering, National Technical University of Athens \\ 9, Iroon Polytechniou str, 15780 Zografou, Greece, email: menegaki@metal.ntua.gr \\ (D) https://orcid.org/0000-0001-8844-3014
}

\begin{abstract}
This paper provides a systematic review of the methodologies used to evaluate the visual impacts of surface mining. The main objectives are: (a) to analyse the scientific literature and identify the most important issues and the methods and tools used; (b) to conduct an analysis using descriptive of statistical methods and qualitative interpretation; and (c) to evaluate the state of knowledge on this particular topic and identify gaps in the literature, to suggest future research directions. The findings of the analysis suggest that there is no single method capable of integrating all dimensions of the landscape and, thus, future research should put more emphasis on incorporating as many factors contributing to the visual impact of mining as possible towards developing holistic approaches.
\end{abstract}

\section{Keywords}

visual impacts; landscape change; mining; quarrying; systematic review

\section{Introduction}

Surface mining causes dramatic changes in the landscape [1,2]. These changes are in several cases permanent, obvious and intense and, therefore, constitute a principal cause of serious public opposition against mining [3]. The severity of the problem led to continuous interest, worldwide, for the development of methods that could assess the magnitude of the visual impact induced by surface mines and quarries. In the "70s and for almost thirty decades, the primary tool used has been the visual quality assessment of the landscape [2] via semi-quantitative methodologies [4-6]. Later on, the development of Geographic Information Systems and other technologies, such as video-imaging, opened new possibilities for the quantification of surface mining-related changes in the landscape. As a result, several methods and approaches were introduced towards measuring alterations on the topography, chromatic contrast of the excavated surface with the surroundings or land cover/land use changes [3,7-11].

There is no doubt that the necessity to evaluate and quantify the visual impacts of surface mining is reflected in the scientific literature. Nevertheless, there is no systematic review article on this topic. Systematic literature review (SLR) is referred to a more or less systematic search of previous studies, which aims to synthesize previous research findings through a replicable, scientific and transparent process [12-16]. SLR can be used for evaluating the state-of-the-art knowledge on a certain issue or research problem to discuss a particular matter or identify knowledge gaps, to examine the validity or accuracy of a theory, to specify a research question, and to move forward the existing knowledge [14-17]. Hence, broadly speaking, SLR may serve as background for an empirical study (e.g. to identify a gap in the literature) [18] or stand-alone attempts [19]. Depending on the primary goal, the method of the SLR may vary [15]. Over the last decades, an increasing number of systematic reviews have been conducting about research on environmental topics in general [20-30] and landscape management in particular [31-34]. Yet, to the best of our knowledge, a systematic review of the visual impacts of surface mining activities upon the landscape has not been carried out, so far, as mentioned.

Within this context, this paper aims to fill this gap in the literature by conducting an SLR about the adverse effects of surface mines and quarries on the landscape quality, based on peer-reviewed scientific publications. More explicitly, the paper has three primary objectives, namely: (a) to analyse the scientific literature and identify the most important issues and the methods and tools implemented towards assessing the impacts of mining projects upon the landscape; (b) to conduct an analysis using descriptive of statistical methods and qualitative interpretation; and (c) to evaluate the state of knowledge on this particular topic and identify gaps in the literature, to suggest future research directions. The rest of the paper is organised as follows: Section 2 presents the methodology implemented to conduct the systematic literature review; Section 3 illustrates the results of the analysis; Section 4 discusses the main findings of the results, and Section 5 summarises the conclusions drawn by this work and suggests future research directions in the topic of interest. 


\section{Methodological approach}

Several guidance documents on how to perform systematic reviews have been published for various science fields $[12,14,15,35-40]$, including environmental sciences [14,39,41-43]. This review process in this work has been performed following the general steps of the guidelines for systematic reviews in environmental management $[39,43]$, which have been adopted in similar applications [34].

The first step towards planning the review is to set the research question. The review is concerned about the impacts of surface mining on the landscape. For the review, the term 'landscape' is defined as "a geographical area, characterised by its content of observable, natural and human-induced, landscape elements", because this definition "encompasses the physical content of areas without necessarily excluding human perception, and allow for a broad inter-disciplinary comparison among approaches" [34]. In this context, the two main research questions addressed by the review are the following:

a. What are the main landscape characteristics studied when assessing the impacts of mining projects upon the landscape?

b. What are the main methods and tools implemented towards assessing the impacts of mining projects upon the landscape?

Besides the research questions, the review planning decided upon the data collection strategy (i.e. search strings and relevant databases to collect the appropriate information) and the inclusion or exclusion criteria.

As regards the data collection strategy, the terms used to search the title, abstract and keywords were: "visual impacts", "visual intrusion", "visual pollution", "chromatic contrast", "landscape alteration", "landscape change", "mining" and "quarrying". Further, the Scopus database was selected because it includes over 75 million records and more than 24,600 titles in the areas of science, technology, medicine, social sciences, art and humanities ${ }^{2}$. Scopus was preferred over Web of Science (WoS) because Scopus includes most of the journals indexed in WoS and has a larger number of exclusive journals than WoS in all fields [44]. The Google Scholar was not originally searched since the search target comprises peer-reviewed articles only and not in publications such as grey literature, presentations, keynotes, extended abstracts, etc.

The initial Scopus search process started with a broad scoping of articles related to the impacts of mining activities on the landscape, using the following string: TITLE-ABS-KEY ("visual impacts" OR "visual intrusion" OR "visual pollution" OR "chromatic contrast" OR "landscape alteration" OR "landscape change" AND mining OR quarrying). A total of 346 records was originally returned. These records were screened, according to the following criteria:

a. $\quad$ Papers published over the past 30 years, i.e. $1990-2020$

b. $\quad$ Papers published in peer-reviewed scientific journals

c. Papers published in English

d. Papers applying or developing methods or tools for assessing the impacts of mining works on the landscape, including land-use/land-cover changes, topographic alteration, chromatic contrast, etc.

e. Papers describing the application of visual impact assessment methods and tools on specific case studies

The first three filtering criteria were applied through the Scopus search. After removing publications before 1990, conference papers, book chapters, etc., and articles not written in English, the number of articles fulfilling the criteria for abstract reading were 194. After reading the article abstract, 43 publications were selected and downloaded for full-text screening. As shown in Fig. 1, 33 articles fulfilled all the criteria and were used in the analysis at the final stage. The studies are listed in Table 1.

\footnotetext{
${ }^{1}$ https://www.elsevier.com/ data/assets/pdf file/0017/114533/Scopus GlobalResearch Factsheet2019 FINAL WEB.pdf
} 
Studies identified through Scopus search $(n=346)$

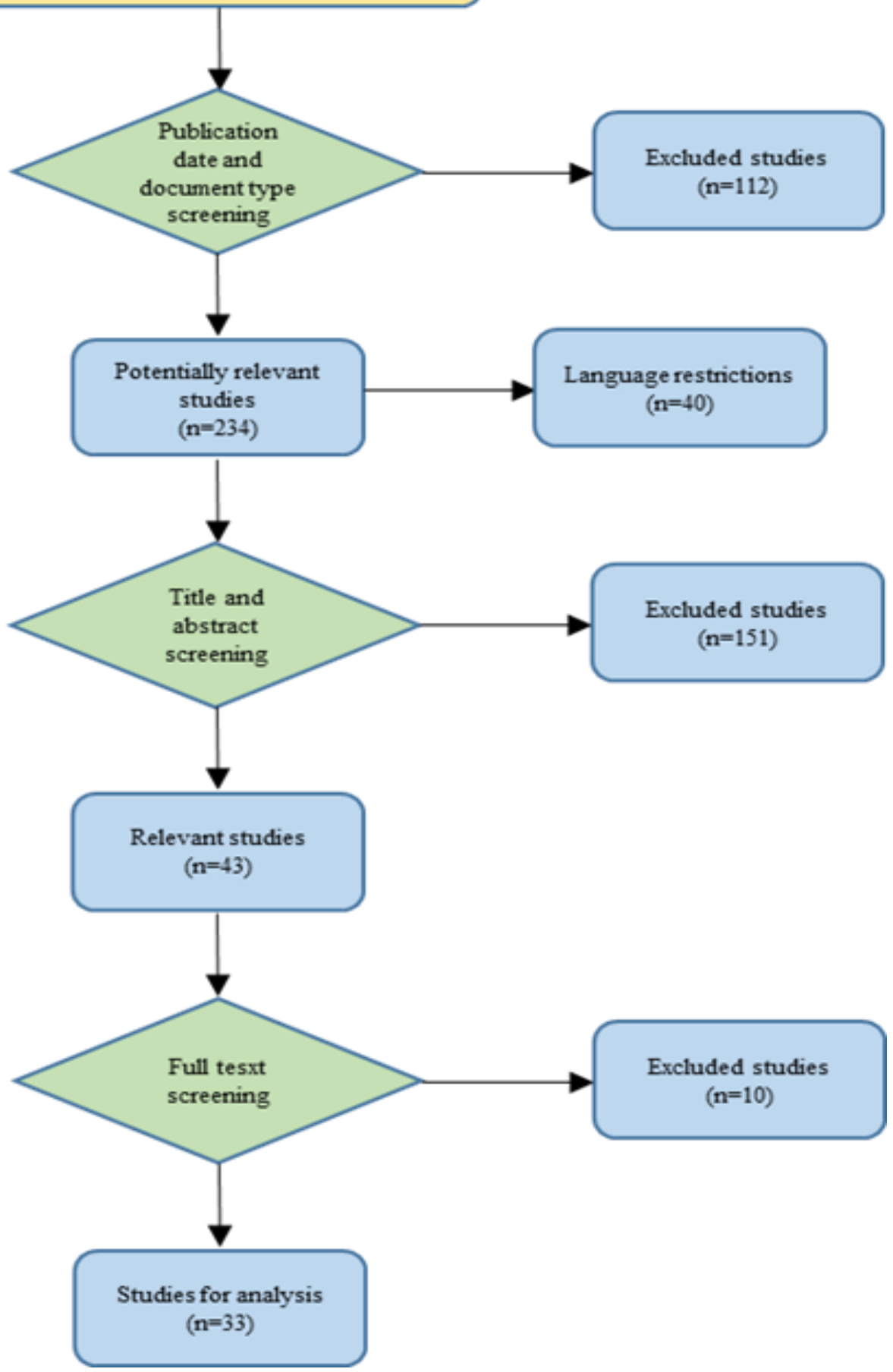

Fig. 1. Filtering of literature 
Table 1. The dataset articles

\begin{tabular}{|c|c|c|}
\hline ID & Title & Reference \\
\hline 1 & A methodology to evaluate the topographic visual alteration on surface mining & [45] \\
\hline 2 & $\begin{array}{l}\text { An analysis of 200-year-long changes in a landscape affected by large-scale surface coal mining: History; } \\
\text { present and future }\end{array}$ & [46] \\
\hline 3 & $\begin{array}{l}\text { Applicability of landscape metrics for the monitoring of landscape change: Issues of scale; resolution and } \\
\text { interpretability }\end{array}$ & [47] \\
\hline 4 & $\begin{array}{l}\text { Application of a multi-stage method to assess the landscape alteration induced by quarrying sites: A } \\
\text { comparative analysis }\end{array}$ & [48] \\
\hline 5 & $\begin{array}{l}\text { Assessing the chromatic contrast in open surface excavations: a comparative study between subjective } \\
\text { and quantitative approaches }\end{array}$ & [3] \\
\hline 6 & $\begin{array}{l}\text { Assessment of the visual impact of marble quarry expansion (1984-2000) on the landscape of Thasos } \\
\text { island; NE Greece }\end{array}$ & [49] \\
\hline 7 & $\begin{array}{l}\text { Assessment of visual impact induced by surface mining with reference to a case study located in Sardinia } \\
\text { (Italy) }\end{array}$ & [50] \\
\hline 8 & Detecting landscape changes pre-and post surface coal mining in Indiana; USA & [51] \\
\hline 9 & $\begin{array}{l}\text { Dynamic changes in landscape pattern in a large-scale opencast coal mine area from } 1986 \text { to 2015: A } \\
\text { complex network approach }\end{array}$ & [52] \\
\hline 10 & Evaluating mining landscape: A step forward & [2] \\
\hline 11 & $\begin{array}{l}\text { Exploring the perceived intrusion of mining into the landscape using the fuzzy cognitive mapping } \\
\text { approach }\end{array}$ & [53] \\
\hline 12 & $\begin{array}{l}\text { Exploring the visual impact from open pit mines applying eye movement analyses on mining landscape } \\
\text { photographs }\end{array}$ & [54] \\
\hline 13 & $\begin{array}{l}\text { Fragmented landscapes of east Bokaro coalfields: A remote sensing based approach highlighting } \\
\text { forestland dynamics }\end{array}$ & [55] \\
\hline 14 & Functional differentiation of landscapes in the area of deep coal mining downsizing in the Ostrava region & [56] \\
\hline 15 & $\begin{array}{l}\text { Image analysis applied to quantitative evaluation of chromatic impact generated by open-pit quarries } \\
\text { and mines }\end{array}$ & [11] \\
\hline 16 & Impact of gold mining on Middle Siberian taiga landscapes from Landsat 7 data & [57] \\
\hline 17 & Impacts of coal mining subsidence on the surface landscape in Longkou city; Shandong Province of China & [58] \\
\hline 18 & Landscape analysis as a tool for surface mining design & [10] \\
\hline 19 & Landscape changes due to quarrying activities as a project parameter for urban planning & [9] \\
\hline 20 & Landscape metrics for assessment of landscape destruction and rehabilitation & [59] \\
\hline 21 & $\begin{array}{l}\text { Landscape pattern changes at a county scale: A case study in Fengqiu; Henan Province; China from } 1990 \\
\text { to } 2013\end{array}$ & [60] \\
\hline 22 & $\begin{array}{l}\text { Mapping the cumulative impacts of long-term mining disturbance and progressive rehabilitation on } \\
\text { ecosystem services }\end{array}$ & [61] \\
\hline 23 & $\begin{array}{l}\text { Multitemporal aerial image analysis for the monitoring of the processes in the landscape affected by deep } \\
\text { coal mining }\end{array}$ & [62] \\
\hline 24 & Quantitative Assessment of Landscape Load Caused by Mining Activity & [63] \\
\hline 25 & $\begin{array}{l}\text { Setting rehabilitation priorities for abandoned mines of similar characteristics according to their visual } \\
\text { impact: The case of Milos Island; Greece }\end{array}$ & [64] \\
\hline 26 & $\begin{array}{l}\text { Spatial distribution of the impact of surface mining on the landscape ecological health of semi-arid } \\
\text { grasslands }\end{array}$ & [65] \\
\hline 27 & $\begin{array}{l}\text { The dynamics of landscape pattern changes in mining areas: The case study of the Adamów-Kozmin } \\
\text { Lignite Basin }\end{array}$ & [8] \\
\hline 28 & $\begin{array}{l}\text { The mining landscape of the Ostrava-Karviná coalfield: Processes of landscape change from the 1830s to } \\
\text { the beginning of the 21st century }\end{array}$ & [66] \\
\hline 29 & $\begin{array}{l}\text { Time-varying elevation change at the Centralia coal mine in Centralia; Washington (USA); constrained } \\
\text { with InSAR; ASTER; and optical imagery }\end{array}$ & [67] \\
\hline 30 & Visibility of surface mining and impact perception & [68] \\
\hline 31 & Visual impact evaluation of mines and quarries: the updated Lvi method & [69] \\
\hline 32 & $\begin{array}{l}\text { Visual impact from quarrying activities: A case study for planning the residential development of } \\
\text { surrounding areas }\end{array}$ & [70] \\
\hline 33 & Visual impact of quarrying in the Polish Carpathians & [7] \\
\hline
\end{tabular}


In order to conduct the analysis, eighteen variables were defined during the reading of the articles included in the final set. The variables are described in Table 2.

Table 2. Variables used for the analysis

\begin{tabular}{|l|l|l|}
\hline Variable & Description & Type \\
\hline Year of publication & Publication year of the article & Discrete \\
\hline Country of origin & Country of the case studied & Nominal \\
\hline Branches of science & The scientific discipline of the affiliation of the first author & Nominal \\
\hline Journal & Title of the journal & Nominal \\
\hline Method & $\begin{array}{l}\text { 'Tailor-made': methodology developed by the authors specifically for } \\
\text { assessing visual impacts of mining projects; 'Landscape metrics': } \\
\text { common indicators used to measure various landscape changes } \\
\text { related to land cover/land uses; 'Other': e.g. questionnaire survey } \\
\text { and EC decision 272 }\end{array}$ & Nominal \\
\hline Input & $\begin{array}{l}\text { DEM (Digital Elevation Model) files, aerial or satellite images, } \\
\text { photographs, topographic maps }\end{array}$ & Nominal \\
\hline Tools & Computational tools or software used & Nominal \\
\hline Mining activity & Type of exploitation such as quarry, metal mine, coal mine, etc. & Nominal \\
\hline Spatial resolution & $\begin{array}{l}\text { The scale addressed in the study, i.e. mine site, mine site and } \\
\text { surroundings, and region }\end{array}$ & Nominal \\
\hline Topographic alteration & The analysis accounts for topographic relief changes & Binary \\
\hline Chromatic contrast & The analysis assesses impacts related to chromatic contrast & Binary \\
\hline Texture/land cover change & $\begin{array}{l}\text { The analysis measures changes in the texture or land cover of the } \\
\text { landscape }\end{array}$ & Binary \\
\hline Land-use change & The analysis measures changes in the land-use & Binary \\
\hline Viewshed & The visibility analysis is based on the viewshed & Binary \\
\hline Viewpoints & The visibility analysis is taken from specific viewpoints & Binary \\
\hline Type of analysis & The analysis provides quantitative results & Binary \\
\hline Total area & The total area studied in km² & Continuous \\
\hline Time periods & Number of periods used to study landscape changes \\
\hline
\end{tabular}

Each study was abstracted and coded, using the variables presented in Table2. However, it was not possible to combine the results using meta-analysis because the included studies follow different methodological approaches and do not share common statistical measures. Therefore, besides simple descriptive statistics, a more qualitative discussion was followed to assess the main findings of the surveys and to compare the results. This process is also known as a qualitative systematic review [15] and refers to using a systematic review process to collect articles, and then a qualitative approach to assess them [71].

\section{Results}

Year of publication, journal title and affiliation

As illustrated in Fig, 2, only one paper was published between 1990 and 2000 by [45]. About one-third of the papers were published between 2000 and 2010, and the rest, i.e. around 65\%, were published during the last ten years. Not surprisingly, almost one-fourth of the research studies have been published by scholars and faculty members from mining departments and another $20 \%$ from environmental and other engineering departments (Fig.3). Also, about $20 \%$ of the articles have been published by authors from departments of geography and environmental sciences, respectively. The rest of the authors of the papers are affiliated with earth sciences, forestry and natural resources departments. Concerning the affiliation of the authors, the papers are published mainly in mining, geography and environmental journals (Table 3). All the journals but the "International Journal of Mining; Reclamation and Environment" which publishes research on mining and environmental engineering, are interdisciplinary in character according to their mission statement. Further, only two of them, namely "Catena" and "Ecological indicators" include the term "landscape" in their statement mission. 


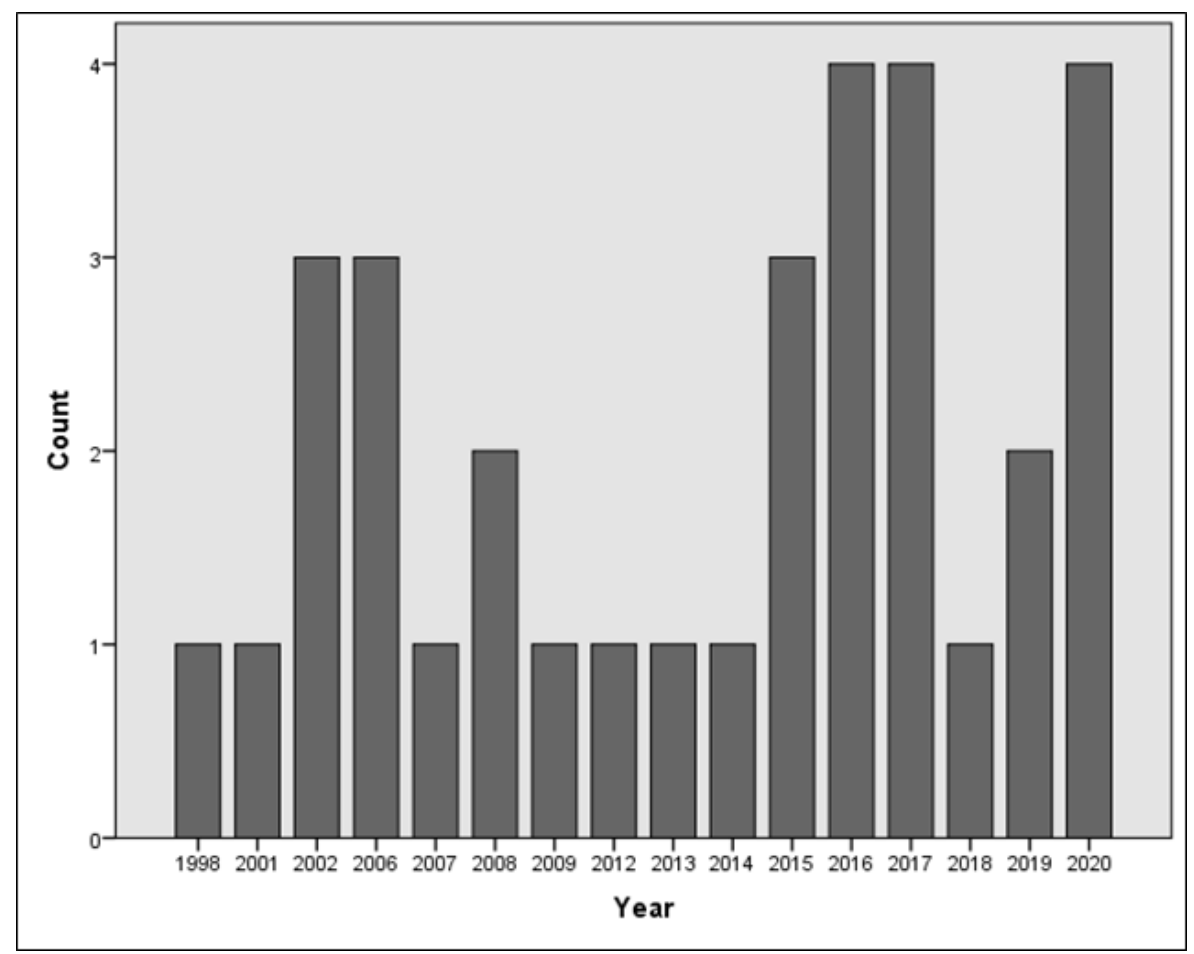

Fig.2. Number of articles published during the period under consideration

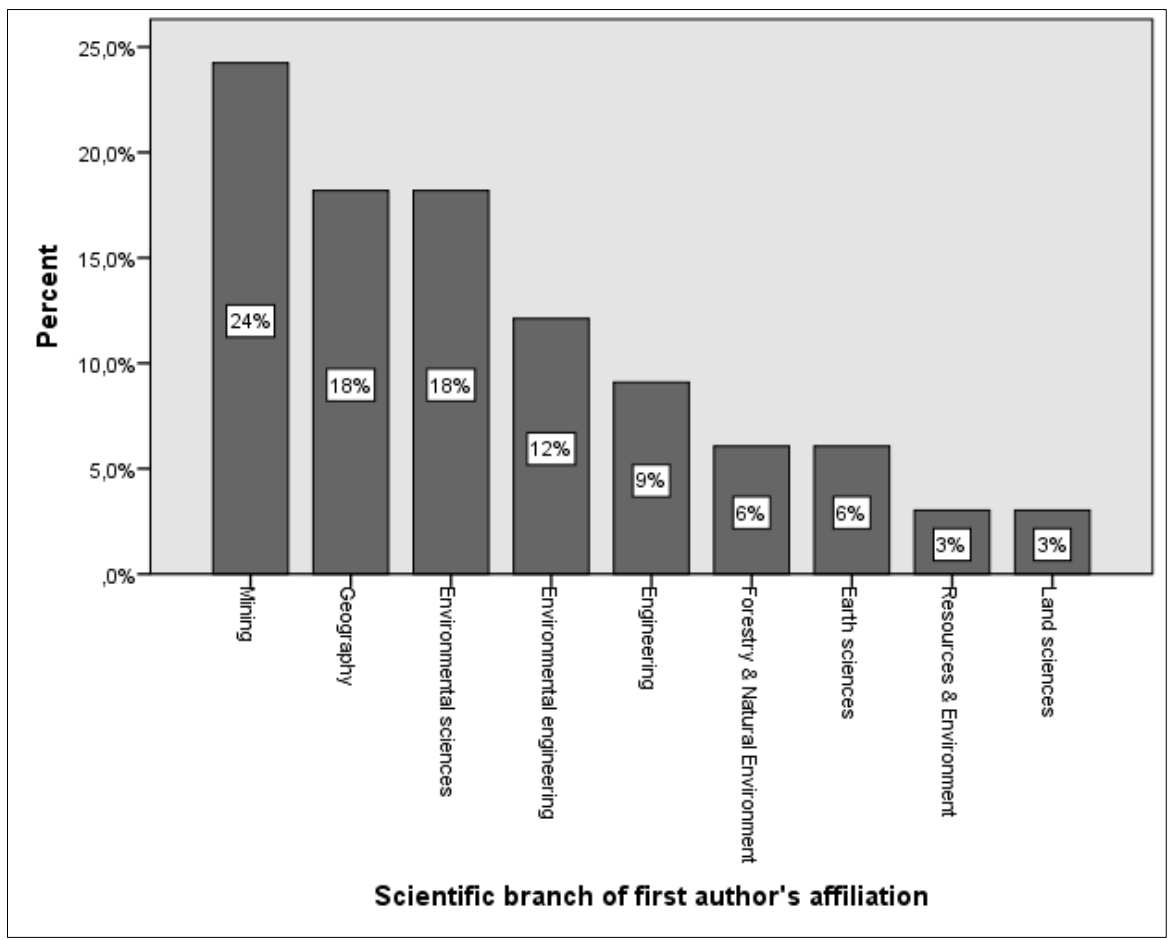

Fig.3. Percentage of articles published according to the first author's affiliation 
Table 3. Titles of journals with two or more papers published

\begin{tabular}{|l|c|}
\hline Journal title & Frequency \\
\hline Environmental Earth Sciences & 3 \\
\hline International Journal of Mining; Reclamation and Environment & 3 \\
\hline Applied Geography & 2 \\
\hline Catena & 2 \\
\hline Ecological Engineering & 2 \\
\hline Ecological Indicators & 2 \\
\hline
\end{tabular}

More than $70 \%$ of the papers have been published by authors affiliated with European universities (Fig.4) and more than half of them (i.e. about $40 \%$ ) have been published by Greek and Italian scholars and faculty members. China follows with $12 \%$ (practically four studies) and the USA with 6\% (two studies).

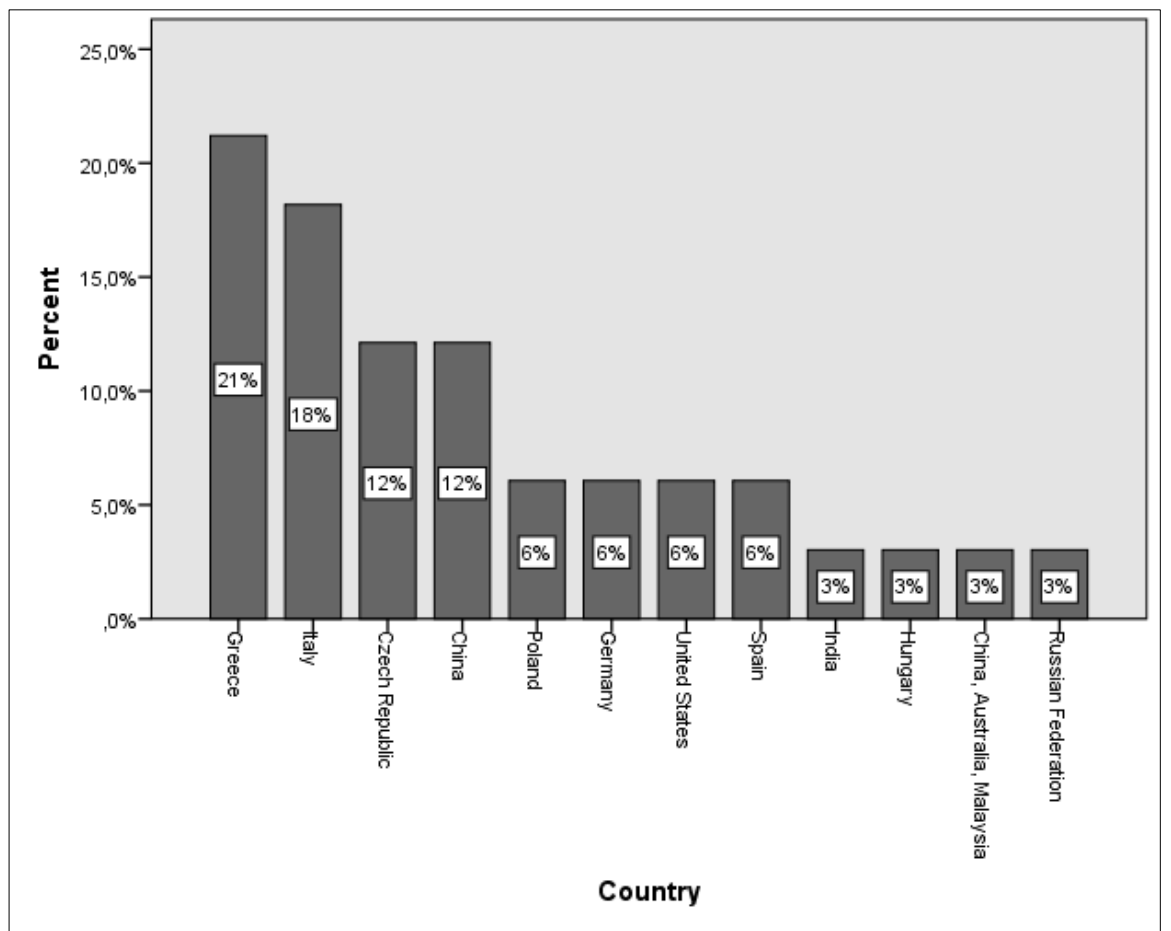

Fig.4. Percentage of articles published according to the authors' country of affiliation

\section{Study area characteristics}

Towards examining the characteristics of the study area, two variables were used that classified the type of exploitation involved in the publication (e.g. quarry, coal mine, etc.) and the scale addressed in the study (i.e. mine site, mine site and surroundings, and region).

About $45.5 \%$ of the publications are related to landscape impacts caused by coal mining activities and about $35 \%$ from quarrying projects. The rest of the cases are referred wither to metal mines or surface mining, in general. Almost half of the research efforts evaluate the visual impacts of surface mining upon the landscape at a local scale, i.e. at the mine site and its adjacent surroundings, while the rest take into consideration larger regions.

Landscape characteristics, methods and tools used

As mentioned in Section 2, the two key research questions aim to identify the main landscape characteristics studied when assessing the impacts of mining projects upon the landscape and the methods and tools used for this purpose. These two issues are closely interrelated and, thus, they are discussed in an integrated manner. As regards the landscape impacts, four group variables were formed, i.e. "Topographic alteration", "Chromatic 
contrast", "Texture/land cover change" and "Land use change". The analysis reveals that there is a clear distinction in the related literature. Almost half of the articles (i.e. 48.5\%) study the alteration of the original topographic relief $(24.4 \%)$ and the colour $(24.4 \%)$ and the rest (i.e. $51.5 \%$ ) are concerned with the land cover or land-use changes (practically these two terms are used interchangeably). Interestingly, there is no publication studying the topographic and chromatic alterations or land cover/land use changes induced by mining works. Only one publication by Quanyuan et al. [58] involves both elevation and land-use changes. Nevertheless, the differences in the original topography are only used to locate subsidence areas, which in turn are used to analyse the landscape impacts before and after the subsidence through changes in arable land, garden land, forest land, etc. Further, two publications do not fall into any of these categories. Misthos et al. [53] recruited a team of experts in mining and landscape engineering and developed a conceptual model of the "mining-landscapesociety" system using Fuzzy Cognitive Mapping (FCM). The model involves twelve mining-, socioeconomic- and landscape-driven factors affecting the perceived nuisance caused by mining projects on the landscape. The authors argue that the model can be helpful to policy-makers and mining practitioners, as it offers the ability to study the impact of each of the factors that give rise to differences in the degree of nuisance employing dynamic simulations or scenario analyses. Nevertheless, it does not provide evidence on the degree of landscape changes. Finally, Misthos et al. [54] used, for the very first time, an eye-tracking experiment to investigate viewing patterns and behaviours of mining landscape photographs. The research focused specifically on how the relative positioning and apparent size of open-pit mines attract the observer's visual attention. The findings of the survey suggest that the lower-left and the centre placement of the quarry in the photograph attract the attention of the viewer. Besides, they found that if the apparent size of the excavated surface decreases so does the clustered visual attention. According to the authors, however, further work is required to explore these issues, combining eye-tracking with subjective methods (e.g. questionnaire surveys).

Almost half of the studies use landscape metrics for assessing mainly changes related to texture, land cover and land uses evolution. About one-third of the studies have used a tailor-made methodology developed by the authors for the assessment of alterations in topography and of chromatic contrast between the mined land and the surrounding area. Further, three publications used the EC decision 272/02 [72] and, more specifically, the visual impact indicator $(x)$, while the rest implemented different techniques, e.g. eye-tracking [54]. The analyses are based primarily on Digital Elevation Model (DEM) files (around 27\%), satellite or aerial images (about 40\%), and photographs (about 24\%). Also, two studies have made use of available land cover databases and one study has involved experts through in-depth interviews. As regards the visibility analysis, five studies (15\%) study landscape changes from certain observer viewpoints and eleven (33\%) conduct a viewshed analysis to find the areas from which the mining works are visible. It is noted that the visibility analysis does not concern studies using landscape metrics. A more detailed analysis is provided hereinafter.

\section{- Topographic alteration}

In total, seven studies analyse the visual impacts of mining through the evaluation of the topographic alteration. Gutierrez Del Alamo \& Chacon [45] developed a methodology to study topography before and after the excavation of the mine area from specific viewpoints using DEM files. In more detail, they evaluate the projections of the original and the altered landscape using three spherical coordinates, namely the real distance between the vertical angle between the observer's visual line with the horizontal plane and the horizontal angle between the observer's visual and the observer-alteration line. Further, they use the fourth indicator to account for the complexity of the contours. The variation of the four parameters for each observer is valued using four $\chi^{2}$ functions and the estimated values can be used to estimate local and global appraisals. Menegaki \& Kaliampakos [10] developed an approach to evaluate the destruction of the original topographic relief due to surface mining activities. The analysis is conducted via GIS and is based on DEM files representing the original contour and the final contour, i.e. the mine topography. The change in elevation and terrain is estimated via five indices that measure the correlation of the original and final contour, the vertical change, the slope difference and the aspect deviation. Later the authors expanded their methodology to assess how this change is perceived [2]. They proposed an approach named LETOPID, which measures: (i) the change in the topographic relief and (ii) the sensitivity of viewing conditions. Viewshed analysis is the tool used to estimate the viewing sensitivity considering the surrounding area, up to a distance of $8 \mathrm{~km}$. The analysis considers the degree of excavation exposure, the distance of the observation point, the surrounding land uses and the observers' sensitivity. Quanyuan et al. [58] used DEM data to identify subsidence areas in a coal-mining region. Nevertheless, their primary goal was to analyse the influence of mining-related subsidence on the landscape and, thus, this study is

https://doi.org/10.32933/Actalnnovations.37.2•ISSN 2300-5599 • (C) 2020 RIC Pro-Akademia - CC BY 
further discussed in Section 3.3.3. Lippiello et al. [9] proposed an assessment procedure for the visual impacts of extractive activities, which is divided into three steps and takes into account: (a) the visible area of the quarry onto the plane view, which varies according to the position of the observer; (b) the surrounding area from which the quarried surface is visible, which is obtained graphically from polar diagrams; and (c) the critical angle above which the excavated area is no longer visible to the observer. The same approach was used by Lippiello et al. [48] in two different case studies. Prush \& Lohman [67] studied elevation changes from coal mines using DEMs that were created by satellite and optical images. The proposed approach, however, does not provide any indicators or parameters to evaluate the degree of impact.

\section{- $\quad$ Chromatic contrast}

Seven studies have applied quantitative approaches for evaluating the chromatic contrast generated by openpit excavations. Pinto et al. [11] developed an image treatment model for the evaluation of the visual contrast between the excavated area and the surrounding landscape. The analysis is based on digital photographs, which are processed with a replicable, objective and automatic procedure. A similar approach, namely the $L v i$ method, was proposed by Dentoni et al. [73] and was used in four studies which are included in the dataset $[7,50,68,70]$. The Lvi method uses digital photographs and image analysis software and estimates the chromatic contrast between the excavation and the surrounding area and the extent of the change in the natural landscape. The analysis is conducted from the most significant viewpoints. An updated version of the Lvi method was proposed quite recently by Dentoni et al. [69]. The updated version eliminates some drawbacks of the original method and improves the repeatability of the evaluation by incorporating two image segmentation algorithms. Menegaki et al. [3] made use of the $C I E L^{*} a^{*} b^{*}$ colour space, to calculate the Euclidean distance between a quarry and its surrounding environment, using digital photographs and image analysis software. The authors tested three different calculation procedures. In the first procedure, the chromatic contrast is estimated between the rock exposed in the quarry face and the dominant landscape elements in the photograph (e.g. sky). In the second procedure, the chromatic contrast is estimated between the quarry and the immediately adjacent surrounding landscape. In the third procedure, the chromatic contrast is estimated between the quarry face and the foreground and the background landscape elements depicted in the image. To explore the effectiveness of each calculation process, a survey was conducted through personal interviews. The sample consisted of 200 undergraduate and postgraduate students, administrative staff and faculty members. The participants were shown a series of photographs and were asked to score the chromatic contrast between the quarry and its surrounding environment. The survey showed that the second approach was closer to the subjective estimates of the survey participants.

- Texture, land cover and land use changes

Almost half of the publications, as already mentioned, have studied the impacts of mining operations on the landscape measuring changes in the land cover or land uses through geometry-based landscape metrics. Herzog et al. [59] explored the landscape impacts induced by agricultural and surface mining activities (more specifically the Espenhain open coal mine) in a $75 \mathrm{~km}^{2}$ study area in Saxony, eastern Germany. To this end, they created digital maps for four periods (i.e. 1912, 1944, 1973, 1989) and adopted eight landscape metrics (e.g. number of patches, mean size of patches, landscape shape index, Simpson's diversity index, etc.) to identify changes in natural landscape units using the FRAGSTATS software. Lausch \& Herzog [47] also investigated the land-use changes in the Espenhain coal mine (as a test area) and in a $700 \mathrm{~km}^{2}$ region in eastern Germany (i.e. Leipzig South). The investigation was conducted based on a time series of digital maps, namely 1912, 1944, 1973 and 1989 for the Espenhain mine, and 1990, 1994, 1996 and 2020 for the Leipzig South region, respectively. Using the FRAGSTATS software, 16 and 27 landscape metrics were calculated in total for the Espenhain area and Leipzig South region, accordingly. Kharuk et al. [57] used Landsat satellite images and field data to assess the impacts of gold mining on the Middle Siberian taiga landscapes. The images were analyzed using Erdas Imagine software and the ratio of the modified territory to the total area was introduced as a means to quantify the impacts of human activities, mining among them, on the landscape. Mouflis et al. (2008) [49] assessed the landscape impacts of marble quarrying on the island of Thasos, Greece, using two Landsat images for the years 1984 and 2000 , respectively. The classification of the landscape elements was performed with Erdas Imagine software and the landscape metrics of quarry patches were estimated via the Patch Analyst extension. In addition to the landscape metrics, the authors conducted a viewshed analysis for the two time periods to quantify the amount of visibility load, i.e. the number of visible quarry perimeter pixels from each location of the island. 
Yang [51] used three Landsat images for the years 1989, 2000 and 2006 to analyze land use/cover changes following reclamation on surface coal mines in southwestern Indiana, USA. The analysis was based on the "fromto" changes among five land use classes and several landscape metrics, calculated through FRAGSTATS.

Quanyuan et al. [58] combined DEM files and remote sensing images for five periods, i.e. 1978, 1984, 1996, 2000, and 2004 , to assess the degree of landscape destruction due to subsidence phenomena in the coal mining area of Longkou in Shandong, China. Using GIS, four landscape metrics (i.e. largest patch index, landscape shape index, patch cohesion index, and distribution index) were calculated to analyze the landscape changes before and after subsidence. Hendrychová \& Kabrna [46] examined landscape transformations in the North Bohemian Basin, Czech Republic, in a coal mining area of $228.48 \mathrm{~km}^{2}$. The analysis was carried out six different time periods (i.e. 1845, 1954, 1975, 1989, 2010 and 2050 based on planned future conditions). Twelve basic land use classes were identified (e.g. water bodies, forest lands, built-up areas, mining areas, etc.) and two specific indices, i.e the coefficient of ecological stability and the landscape diversity index, were analyzed in a GIS environment. Fan \& Ding [60] used Landsat images for four periods (1990, 2002, 2009 and 2013) of Fengqiu County, China, to investigate landscape pattern changes and their driving forces. Five different land uses were identified (i.e. cultivated land, forest land, water bodies, settlements and mining sites and unused land). The landscape pattern changes between the time periods were analyzed utilizing five main landscape indices using FRAGSTATS and introduced the "Entropy model" to evaluate the whole land-use change.

Popelková \& Mulková [62] used a series of aerial images combined with the EU CORINE Land Cover to study the landscape impacts of coal mining at the Ostrava-Karviná region, Czech Republic, in an area of $197.16 \mathrm{~km}^{2}$. The changes in the land cover were assessed using visual photointerpretation for seven different processes (i.e. urbanization, intensification of agriculture, afforestation, deforestation, flooding, abandonment and drainage) and three different time periods between 1947-2009. Using the same approach enriched by cadastral maps and historical aerial photographs, the authors extended the analysis over a longer period of time and evaluated temporal-spatial land cover changes for three time periods, i.e. 1836-1947, 1947-1971 and 1971-2009 $[66]$.

Upgupta \& Singh [55] studied land cover changes in the East Bokaro coalfield region, in India, using Landsat images of three time periods (i.e. 1972, 2001 and 2016). The analysis was performed for an area of $259 \mathrm{~km}^{2}$ in a GIS environment using FRAGSTATS and, in total, twelve landscape metrics were calculated. Further, temporal changes for six different land cover classes, including mining, were analyzed. Csüllög et al. [63] assessed the landscape impacts of mining using a landscape load index as a proxy. The analysis was carried out in a GIS environment using a database of mining claims and deposits of mining waste. The proposed method offers the means to conduct comparative analyses between different areas about problems and landscape-use conflicts caused by mining. Nevertheless, it does not measure land use or land cover changes in absolute terms.

Fagiewicz \& Łowicki [8] examined land-use changes in the Adamów-Koźmin Lignite Basin using maps and orthophotomaps. The landscape pattern analysis was carried out in a total area of $152.56 \mathrm{~km}^{2}$, for two periods, that is 1940 (the period preceding the lignite mining) and 2011. Seven land cover classes following the EU CORINE Land Cover and ten landscape metrics were considered.

Wang et al. [61] mapped and quantified changes in an area of $76.62 \mathrm{~km}^{2}$ which is part of one of the largest surface coal mines of Australia, namely the Curragh mine. The study focused on land-cover changes associated with four ecosystem services (water yield, air quality regulation, soil conservation and carbon sequestration) in four time periods (1989, 1997, 2005 and 2013). Totally, 56 Landsat images were used between 1988 and 2015. Four landscape metrics were analyzed in FRAGSTATS and topographic changes were studied using DEM files. Wu et al. [65] evaluated the impact of surface mining in Shengli surface mines, China, based on six Landsat images for the years 2002, 2005, 2008, 2011, 2014 and 2017. The methodology includes the development of a new algorithm, namely "the Modified Landscape Disturbance Index (MLDI)", which is calculated by three other measurements, i.e. the Landscape Disturbance Index, the Landscape Ecological Health and the Distance to the Surface Mining Landscape. Zhang et al. [52] analyzed land-use changes in an area of $517.48 \mathrm{~km}^{2}$ at the Pingshuo coal mine region, based on remote sensing images for six periods (i.e. 1986, 1996, 2000, 2009, 2013 and 2015). Three first-level and eleven second-level land types were identified and two indices, namely the landscape change index and the patch level selection index, were calculated using ten and six measurements, respectively.

https://doi.org/10.32933/ActaInnovations.37.2• ISSN 2300-5599 • C 2020 RIC Pro-Akademia - CC BY 


\section{Impact}

The review reveals a pattern of three substantially different groups of methodological approaches. The first group includes studies associated with changes in the topographic relief. With two exceptions [58,67], these studies involve computational processes and estimate quantitative indicators related to elevation changes between the original and altered landscape and the visibility of the mining operations. However, none of these approaches includes landscape elements nor they account for aesthetic, cultural or ecological values. The methodologies of [9], [45] and [48] conduct the analysis from specific viewpoints and, thus, are prone to subjective bias, while the methodology of [2] takes into account the total surrounding zone (up to a distance of $8 \mathrm{~km}$ ). The second group of studies $[3,7,11,50,68-70]$ focuses exclusively on the evaluation of the visual contrast between the mine/quarry face and the surrounding environment. All the proposed approaches are based on digital photographs processed with image analysis software. Although these methods suggest a replicable, objective and automatic procedure that is easy to implement, some limitations exist. The perceived visual contrast (and, consequently, the findings of the analysis) is affected by the atmospheric conditions and the season of the year $[11,68]$ as well as by the diversity of landscape features, the distance from mountain ridges, the existence of other man-made activities, etc. [53]. In other words, there exists subjectivity (e.g. when selecting the viewpoints from which the analysis shall be made), variability (e.g. due to the illumination conditions or the season of the year) and, most importantly, heterogeneity amongst the observers. So it is not surprising, as research efforts have shown [3], that only a small part of the observers' beliefs may be explained through objective methods. The third group of studies incorporates research efforts that emphasize the use of landscape metrics. The impacts of mining operations (mainly coal mining) are evaluated solely through the prism of land cover and/or land-use changes (these two terms are usually used interchangeably). Critical aspects of the visual impacts of mining, such as the destruction of the original topography and the visibility of the mining operations from the surrounding area are neglected. Only [58] evaluated topographic alterations but only as a means to analyze landscape changes in mine subsidence areas and [49] conducted a viewshed analysis to quantify the visibility load of quarrying without connecting, however, the two elements (i.e. the land-use change and the visibility) directly.

Also, a very clear connection is identified between these three groups and the scientific disciplines of the authors. More analytically, five out of seven publications in topographic alteration and six out of seven publications in chromatic contrast have been published by authors who work in engineering (mining or environmental) departments, while fifteen out of seventeen studies investigating land cover/land use changes via landscape metrics have been published by scholars who work in departments of geography and earth or environmental sciences. This trend is related not only to the scientific background of the authors but also to the scope of the research efforts. Scholars with engineering background aim mainly to come up with quantitative indicators that directly measure and compare variations in principal landscape characteristics, such as topography. This approach allows them to identify the most efficient mine exploitation or rehabilitation plans in terms of visual impact management and to design, if needed, appropriate preventive or mitigation measures. On the other hand, geographers and environmental scientists are primarily concerned with the environmental footprint of mining. Thus, they evaluate impacts related to spatial mosaics of interacting biophysical and socioeconomic landscape components. These approaches adopt a biophysical concept for the landscape and are closer to 'mapping' than 'assessment' [34]. They are combined with GIS-overlay techniques, which are widely used in biophysical approaches, and can be easily automated [74]. Yet, they are based on a priori selection of land use types and indicators that hinders subjectivity for the characterisation process.

Based on the above remarks, it becomes apparent that every method has advantages, disadvantages and constraints. Therefore, no single method is capable of integrating all dimensions of the landscape without compromises. Further, it could be argued that the existing methodological approaches are rather complementary than competitive and the selection of the method will depend on the characteristics, purposes and specific needs of each application. In this direction, future research efforts should put more emphasis on incorporating as many factors contributing to the visual impact of mining as possible towards developing holistic approaches.

\section{Conclusions}

Assessing the impacts of surface mining activities upon the landscape is far from being a simple and straightforward process because of the fuzzy, complex, subjective and multidimensional character of the landscape itself [53]. As Olwig et al. [75] mention: “...in any discussion of landscape characterization, the elephant 
in the room is the question of just what is landscape..." and this raises the question of "... whether, under what conditions ..... and to what degree the presence of an open pit causes visual nuisance..." (cited by [53]).

The findings of this survey suggest that the main landscape characteristics considered when assessing the visual impacts of mining projects and the methods used for this purpose depend on their scientific rooting, just like in the case of methods used for landscape characterization and mapping [34]. Specifically, three different categories of landscape impacts were identified, namely "Topographic alterations", "Chromatic contrast", and "Texture/land cover or land-use change" and an equal number of approaches were recognized, i.e. (a) approaches aiming to quantify topographic alterations and the visibility of the mining operations; (b) approaches aiming to evaluate the chromatic contrast between the excavation and the surrounding landscape; and (c) approaches aiming to map landscape elements and to identify disturbances by mining activities using landscape metrics and statistical analyses. The first two categories are rooted in engineering disciplines and the latter is established primarily in disciplines of geography and ecology.

All things considered, future research efforts should incorporate as many factors as possible towards developing holistic approaches capable of evaluating the visual impacts of mining projects. In the same direction, they should consider establishing quantitative criteria and/or thresholds against which the visual impacts from mining projects can be rated.

\section{Conflict of interest}

There are no conflicts to declare.

\section{Acknowledgments}

This research has not been supported by any external funding.

\section{References}

[1] Dentoni V, Grosso B, Massacci G. Assessment of visual impact due to surface mining with the Lvi method. Legis. Technol. Pract. Mine L. Reclam. - Proc. Beijing Int. Symp. L. Reclam. Ecol. Restoration, Lr. 2014, Department of Civil and Environmental Engineering and Architecture, University of Cagliari, Cagliari, Italy: 2015, p. 527-34.

[2] Menegaki ME, Kaliampakos DC. Evaluating mining landscape: A step forward. Ecological Engineering 43 (2012), 26-33.

[3] Menegaki M, Koutiva I, Kaliampakos D. Assessing the chromatic contrast in open surface excavations: a comparative study between subjective and quantitative approaches. International Journal of Mining, Reclamation and Environment 29 (2015), 112-24.

[4] USDA. The Visual Management System. National Forest Landscape Management. Agricultur. Washington.: U.S. Government Printing Office; 1973.

[5] Bureau of Land Management. Visual Resource Management. Manual 840. U.S. Dept. of the Interior, U.S.A. Government Printing Office; 1980.

[6] Province of British Columbia. Visual Landscape Inventory: Proceedings and Standards Manual. 1997.

[7] Dentoni V, Massacci G, Radwanek-Bak BD. Visual impact of quarrying in the Polish Carpathians. Geological Quartarly 50 (2006), 383-390.

[8] Fagiewicz K, Łowicki D. The dynamics of landscape pattern changes in mining areas: The case study of the Adamów-Koźmin Lignite Basin. Quaestiones Geographicae 38 (2019), 151-162.

[9] Lippiello D, Degan GA, Pinzari M. Landscape changes due to quarrying activities as a project parameter for urban planning. International Journal of Sustainable Development and Planning 10 (2015), 843-862.

[10] Menegaki ME, Kaliampakos DC. Landscape analysis as a tool for surface mining design. Environmental and Planning B: Urban Analytics and City Science 33 (2006) 185-196.

[11] Pinto V, Font X, Salgot M, Tapias J, Mañá T. Image analysis applied to quantitative evaluation of chromatic impact generated by open-pit quarries and mines. Environmental Geology 41 (2002) 495-503.

[12] Hutton B, Salanti G, Caldwell DM, Chaimani A, Schmid CH, Cameron C, Ioannidis JPA, Straus S, Thorlund K, Jansen JP, Mulrow C, Catalá-Lopez F, Gotzsche PC, Dickersin K, Boutron I, Altman, DG, Moher D. The PRISMA extension statement for reporting of systematic reviews incorporating network meta-analyses of health care interventions: Checklist and explanations. Annals of Internal Medicine 162 (2015), 777-784.

[13] Cooper C, Booth A, Varley-Campbell J, Britten N, Garside R. Defining the process to literature searching in systematic reviews: A literature review of guidance and supporting studies. BMC Medical Research Methodology 18 (2018), 85.

[14] Mengist W, Soromessa T, Legese G. Method for conducting systematic literature review and meta-analysis

https://doi.org/10.32933/Actalnnovations.37.2• ISSN 2300-5599 • ( 2020 RIC Pro-Akademia - CC BY 
for environmental science research. MethodsX 7 (2020), 100777.

[15] Snyder H. Literature review as a research methodology: An overview and guidelines. Journal of Business Research 104 (2019), 333-339.

[16] Tranfield D, Denyer D, Smart P. Towards a Methodology for Developing Evidence-Informed Management Knowledge by Means of Systematic Review. British Journal of Managment 14 (2003), 207-222.

[17] Webster J, Watson RT. Analyzing the Past to Prepare for the Future: Writing a Literature Review. MIS Quartarly 26 (2002), xiii-xxiii.

[18] Templier M, Paré G. A framework for guiding and evaluating literature reviews. Communications of Association for Information Systems 37 (2015), https://doi.org/10.17705/1cais.03706.

[19] Rousseau DM, Manning J, Denyer D. Evidence in Management and Organizational Science: Assembling the Field's Full Weight of Scientific Knowledge through Syntheses. Academy of Management Annals 2 (2011), 475515.

[20] Brandt JS, Buckley RC. A global systematic review of empirical evidence of ecotourism impacts on forests in biodiversity hotspots. Current Opinion in Environmental Sustainability 32 (2018), 112-118.

[21] Brooks J, Waylen KA, Mulder MB. Assessing community-based conservation projects: A systematic review and multilevel analysis of attitudinal, behavioral, ecological, and economic outcomes. Environmental Evidence 2 (2013), 2.

[22] Timpane-Padgham BL, Beechie T, Klinger T. A systematic review of ecological attributes that confer resilience to climate change in environmental restoration. PLoS One 12 (2017), e0173812.

[23] Clucas B, Parker ID, Feldpausch-Parker AM. A systematic review of the relationship between urban agriculture and biodiversity. Urban Ecosystems 21 (2018), 635-643.

[24] De Araujo Barbosa CC, Atkinson PM, Dearing JA. Remote sensing of ecosystem services: A systematic review. Ecological Indicators 52 (2015), 430-443.

[25] Harrison PA, Berry PM, Simpson G, Haslett JR, Blicharska M, Bucur M, Dunford R, Egoh B, Garcia-Llorente M, Geamana N, Geertsema W, Lommelen E, Meiresonne L, Turkelboom F, Linkages between biodiversity attributes and ecosystem services: A systematic review. Ecosystem Services 9 (2014), 191-203.

[26] Himes-Cornell A, Pendleton L, Atiyah P. Valuing ecosystem services from blue forests: A systematic review of the valuation of salt marshes, sea grass beds and mangrove forests. Ecosystem Services 30 (2018), 36-48.

[27] Lowry E, Rollinson EJ, Laybourn AJ, Scott TE, Aiello-Lammens ME, Gray SM, Mickley J, Gurevitch J. Biological invasions: A field synopsis, systematic review, and database of the literature. Ecology and Evolution 3 (2013), 182-196.

[28] Mantyka-pringle CS, Martin TG, Rhodes JR. Interactions between climate and habitat loss effects on biodiversity: A systematic review and meta-analysis. Glob Change Biology 18 (2012), 1239-1252.

[29] Savilaakso S, Garcia C, Garcia-Ulloa J, Ghazoul J, Groom M, Guariguata MR, Laumonier Y, Nasi R, Petrokofsky G, Snaddon J, Zrust M. Systematic review of effects on biodiversity from oil palm production. Environmental Evidence 3 (2014), 4.

[30] Shepard CC, Crain CM, Beck MW. The protective role of coastal marshes: A systematic review and metaanalysis. PLoS One 6 (2011) e27374.

[31] Englund O, Berndes G, Cederberg C. How to analyse ecosystem services in landscapes - A systematic review. Ecological Indicators 73 (2017), 492-504.

[32] Kabisch N, Qureshi S, Haase D. Human-environment interactions in urban green spaces - A systematic review of contemporary issues and prospects for future research. Environmental Impact Assessment Review 50 (2015), 25-34.

[33] Plieninger T, Draux H, Fagerholm N, Bieling C, Bürgi M, Kizos T, Kuemmerle T, Primdahl J, Verburg PH, The driving forces of landscape change in Europe: A systematic review of the evidence. Land Use Policy 57 (2016), 204-214.

[34] Simensen T, Halvorsen R, Erikstad L. Methods for landscape characterisation and mapping: A systematic review. Land Use Policy 75 (2018), 557-569.

[35] Davis J, Mengersen K, Bennett S, Mazerolle L. Viewing systematic reviews and meta-analysis in social research through different lenses. Springerplus 3 (2014), 511.

[36] Higgins JP, Green S. Cochrane Handbook for Systematic Reviews of Interventions: Cochrane Book Series. 2008.

[37] Liberati A, Altman DG, Tetzlaff J, Mulrow C, Gøtzsche PC, loannidis JPA, Clarke M, Devereaux PJ, Kleijnen J, Moher D. The PRISMA statement for reporting systematic reviews and meta-analyses of studies that evaluate health care interventions: explanation and elaboration. The BMJ, 339 (2009), b2700. 
[38] Palmatier RW, Houston MB, Hulland J. Review articles: purpose, process, and structure. Journal of the Academy of Marketing Science 46 (2018), 1-5.

[39] Pullin AS, Stewart GB. Guidelines for systematic review in conservation and environmental management. Conservation Biology 20 (2006), 1647-1656.

[40] Xiao Y, Watson M. Guidance on Conducting a Systematic Literature Review. Journal of Planning Educational Research 39 (2019), 93-112.

[41] Berrang-Ford L, Pearce T, Ford JD. Systematic review approaches for climate change adaptation research. Regional Environmental Change 15 (2015), 755-769.

[42] Collaboration for Environmental Evidence. Guidelines and Standards for Evidence Synthesis in Environmental Management Version 5.0. 2018.

[43] Collaboration for Environmental Evidence. Guidelines for Systematic Review and Evidence Synthesis in Environmental Management. 2013.

[44] Mongeon P, Paul-Hus A. The journal coverage of Web of Science and Scopus: a comparative analysis. Scientometrics 106 (2016), 213-228.

[45] Gutierrez Del Alamo LF, Chacon E. A methodology to evaluate the topographic visual alteration on surface mining. International Journal of Surface Mining, Reclamation and Environment 12, 1 (1998), 41-45.

[46] Hendrychová M, Kabrna M. An analysis of 200-year-long changes in a landscape affected by large-scale surface coal mining: History, present and future. Applied Geography 74 (2016), 151-159.

[47] Lausch A, Herzog F. Applicability of landscape metrics for the monitoring of landscape change: Issues of scale, resolution and interpretability. Ecological Indicators 2, (2002), 3-15.

[48] Lippiello D, Degan GA, De Agostini M, Pinzari M. Application of a multi stage method to assess the landscape alteration induced by quarrying sites: A comparative analysis. American Journal of Environmental Sciences 12 (2016), 317-327.

[49] Mouflis GD, Gitas IZ, Iliadou S, Mitri GH. Assessment of the visual impact of marble quarry expansion (19842000) on the landscape of Thasos island, NE Greece. Landscape and Urban Planning 86, 1 (2008), 92-102.

[50] Dentoni V, Massacci G. Assessment of visual impact induced by surface mining with reference to a case study located in Sardinia (Italy). Environmental Earth Sciences 68 (2013), 1485-1493.

[51] Yang JJ. Detecting landscape changes pre-and post surface coal mining in Indiana, USA. Geographic Information Sciences 14 (2008), 36-43.

[52] Zhang M, Wang J, Li S, Feng D, Cao E. Dynamic changes in landscape pattern in a large-scale opencast coal mine area from 1986 to 2015: A complex network approach. Catena 194 (2020), 104738.

[53] Misthos L-M, Messaris G, Damigos D, Menegaki M. Exploring the perceived intrusion of mining into the landscape using the fuzzy cognitive mapping approach. Ecological Engineering 101 (2017), 60-74.

[54] Misthos L-M, Pavlidis A, Karabassakis E, Menegaki M, Krassanakis V, Nakos B. Exploring the visual impact from open pit mines applying eye movement analyses on mining landscape photographs. International Journal of Mining, Reclamation and Environment 34 (2020), 609-624.

[55] Upgupta S, Singh PK. Fragmented landscapes of east Bokaro coalfields: A remote sensing based approach highlighting forestland dynamics. Applied Ecology and Environmental Research 15 (2017), 1313-1326.

[56] Lacina J. Functional differentiation of landscapes in the area of deep coal mining downsizing in the Ostrava region. Moravian Geographical Reports 14 (2006), 3-15.

[57] Kharuk VL, Ranson KJ, Im ST, Fedotova E V. Impact of gold mining on Middle Siberian taiga landscapes from Landsat 7 data. Mapping Sciences and Remote Sensing 39 (2002), 139-156.

[58] Quanyuan W, Jiewu P, Shanzhong Q, Yiping L, Congcong H, Tingxiang L, Limei H. Impacts of coal mining subsidence on the surface landscape in Longkou city, Shandong Province of China. Environmental Earth Sciences 59 (2009), 783-791.

[59] Herzog F, Lausch A, MÜller E, Thulke H-H, Steinhardt U, Lehmann S. Landscape metrics for assessment of landscape destruction and rehabilitation. Environmental Management 27 (2001), 91-107.

[60] Fan Q, Ding S. Landscape pattern changes at a county scale: A case study in Fengqiu, Henan Province, China from 1990 to 2013. Catena 137 (2016), 152-160.

[61] Wang Z, Lechner AM, Yang Y, Baumgartl T, Wu J. Mapping the cumulative impacts of long-term mining disturbance and progressive rehabilitation on ecosystem services. Science of The Total Environment 717 (2020), 137214.

[62] Popelková R, Mulková M. Multitemporal aerial image analyesis for the monitoring of the processes in the landscape affected by deep coal mining. European Journal of Remote Sensing 49 (2016), 973-1009.

[63] Csüllög G, Horváth G, Tamás L, Szabó M, Munkácsy B. Quantitative Assessment of Landscape Load Caused

https://doi.org/10.32933/Actalnnovations.37.2•ISSN 2300-5599 • (C) 2020 RIC Pro-Akademia - CC BY 
by Mining Activity. European Countryside 9 (2017), 230-244.

[64] Mavrommatis E, Menegaki M. Setting rehabilitation priorities for abandoned mines of similar characteristics according to their visual impact: The case of Milos Island, Greece. Journal of Sustainable Mining 16 (2017), 104-113.

[65] Wu Z, Lei S, Lu Q, Bian Z, Ge S. Spatial distribution of the impact of surface mining on the landscape ecological health of semi-arid grasslands. Ecological Indicators 111 (2020), 105996.

[66] Popelková R, Mulková M. The mining landscape of the Ostrava-Karviná coalfield: Processes of landscape change from the 1830s to the beginning of the 21st century. Applied Geography 90 (2018), 28-43.

[67] Prush VB, Lohman RB. Time-varying elevation change at the centralia coal mine in centralia, Washington (USA), constrained with InSAR, ASTER, and optical imagery. IEEE Journal of Selected Topics in Applied Earth Observations and Remote Sensing 8 (2015), 919-925.

[68] Dentoni V, Massacci G. Visibility of surface mining and impact perception. I International Journal of Mining, Reclamation and Environment 21 (2007), 6-13.

[69] Dentoni V, Grosso B, Massacci G, Soddu GP. Visual impact evaluation of mines and quarries: the updated Lvi method. Environmental Earth Sciences 79 (2020), 100.

[70] Alfaro Degan G, Lippiello D, Picciolo L, Pinzari M. Visual impact from quarrying activities: A case study for planning the residential development of surrounding areas. WIT Transactions on Ecology and the Environment, 181 (2014), 125-136.

[71] Grant MJ, Booth A. A typology of reviews: An analysis of 14 review types and associated methodologies. Health Information \& Libraries Journal 26 (2009), 91-108.

[72] European Commission. Commission Decision 2002/272/EC of 25 March 2002 establishing the ecological criteria for the award of the Community eco-label to hard floor-coverings. Official Journal of European Union 2002:13-27.

[73] Dentoni V, Massacci G, Asquer C. Visibility of surface mining and impact perception. Proceedings of the 14th International Symposium on Mine Planning and Equipment Selection, MPES 2005 and the 5th International Conference on Computer Applications in the Minerals Industries, CAMI 2005, Department of Geoengineering and Environmental Technologies, University of Cagliari, Italy: 2005.

[74] Brabyn L. Classifying landscape character. Landscape Research 34 (2009), 299-321.

[75] Olwig KR, Dalglish C, Fairclough G, Herring P. Introduction to a special issue: the future of landscape characterisation, and the future character of landscape - between space, time, history, place and nature. Landscape Research 41 (2016), 169-174. 